\title{
Potential biological therapies for severe preeclampsia: a systematic review and meta-analysis
}

Sophia Grimes ${ }^{1}$, Kira Bombay ${ }^{1}$, Andrea Lanes ${ }^{1,2}$, Mark Walker ${ }^{1,2,3}$ and Daniel J. Corsi ${ }^{1,2,4,5^{*}}$ (D)

\begin{abstract}
Background: Preeclampsia remains a significant danger to both mother and child and current prevention and treatment management strategies are limited. The objective of this systematic review was to investigate the current literature on evidence for the use of the regenerative capacity of mesenchymal stem cell (MSC) therapy, the anticoagulant activity of antithrombin (AT), or the free radical scavenging activity of alpha-1-microglobulin (A1M) as potential novel treatments for severe preeclampsia and Hemolysis, Elevated Liver enzymes, Low Platelet count (HELLP).
\end{abstract}

Method: We conducted a systematic review of potential biological therapies for preeclampsia. We screened MEDLINE and Embase from inception through May 2017 for studies using AT, A1M or MSCs as potential treatments for preeclampsia and/or HELLP. A meta-analysis was performed to pool data from randomized control trials (RCTs) with homogenous outcomes using the inverse variance method. The Newcastle-Ottawa Scale, the Cochrane risk of bias tool for RCTs, and SYRCLE's risk of bias tool for animal studies were used to investigate potential bias of studies.

Results: The literature search retrieved a total of 1015 articles, however, only 17 studies met the selection criteria: AT ( $n$ $=9,8$ human and 1 animal); A1M ( $n=4,3$ animal and 1 ex-vivo); and, MSCs ( $n=4,3$ animal and 1 ex-vivo). A metaanalysis of AT therapy versus placebo and a meta-analysis for AT therapy with heparin versus heparin alone did not show significant differences between study groups. Animal and ex-vivo studies demonstrated significant benefits in relevant outcomes for A1M and MSCs versus control treatments. Most RCT studies were rated as having a low risk of bias across categories with some studies showing an unclear risk of bias in some categories. The two cohort studies both received a total of four out of nine stars (a rating of "poor" quality). Most animal studies had an unclear risk of bias across most categories, with some studies having a low risk of bias in some categories.

Conclusions: The findings of this review are strengthened by rigorous systematic search and review of the literature. Results of our meta-analyses do not currently warrant further exploration of AT as a treatment of preeclampsia in human trials. Results of animal and ex-vivo studies of A1M and MSCs were encouraging and supportive of initiating human investigations.

Keywords: Preeclampsia, Mesenchymal stem cells, Antithrombin, Alpha-1-microglobulin, Gestational hypertension, Systematic review, Meta-analysis

\footnotetext{
* Correspondence: dcorsi@ohri.ca

'OMNI Research Group, Clinical Epidemiology Program, Ottawa Hospital

Research Institute, Ottawa, Ontario, Canada

${ }^{2}$ School of Epidemiology, Public Health and Preventive Medicine, University

of Ottawa, Ottawa, Ontario, Canada

Full list of author information is available at the end of the article
}

(c) The Author(s). 2019 Open Access This article is distributed under the terms of the Creative Commons Attribution 4.0 International License (http://creativecommons.org/licenses/by/4.0/), which permits unrestricted use, distribution, and reproduction in any medium, provided you give appropriate credit to the original author(s) and the source, provide a link to the Creative Commons license, and indicate if changes were made. The Creative Commons Public Domain Dedication waiver (http://creativecommons.org/publicdomain/zero/1.0/) applies to the data made available in this article, unless otherwise stated. 


\section{Background}

Preeclampsia (PE) is a condition that arises solely in pregnancy [1]. It is characterized by high blood pressure and proteinuria, and can have fatal consequences [1]. PE can become severe when the diastolic blood pressure reaches or exceeds $110 \mathrm{mmHg}$ [1]. Ten percent of women have high blood pressure during pregnancy, and PE complicates between 2 and $8 \%$ of pregnancies [2]. Overall, 10 to $15 \%$ of direct maternal deaths are associated with PE and eclampsia [2]. Although the etiology of PE is not confirmed, there are numerous hypotheses related to disturbed placental function. Current research suggests that PE evolves in two pathophysiological stages [3]. In the first stage, poor spiral artery adaption due to decreased trophoblast ingrowth of the myometrial arteries leads to decidua-associated vascular changes, causing oxidative stress which damages the placenta [3]. As a result, there is uneven placental flow and reduced oxygen concentration [3]. The second stage of preeclampsia is associated with maternal endothelial dysfunction which precedes the onset of clinical manifestations including hypertension, proteinuria, and edema [3]. HELLP (hemolysis, elevated liver enzymes, and low platelet count) syndrome is serious for the mother and the fetus [4]. HELLP occurs in $0.2-0.8 \%$ of pregnancies and in $70-80 \%$ of cases it coexists with $\mathrm{PE}$ [4]. It is characterized by prominent endothelial damage in the liver [5]. The endothelial damage triggers an immune response inducing thrombotic microangiopathy with platelet-fibrin thrombi in micro-vessels [5]. The resulting angiopathy leads to consumption of circulating platelets, causes hemolysis in affected micro vessels and reduces portal flow in liver; leading to life threatening events [5].

The only confirmed treatment for PE and/or HELLP is induction of delivery, which often results in preterm birth [2]. In addition, babies that are born with low birthweight or congenital anomalies may have higher rates of coronary heart disease, high blood pressure, high cholesterol concentrations, and abnormal glucose-insulin metabolism [6]. There is ongoing research being performed on potential biological therapies for HELLP and severe PE. Three approaches that are currently being investigated include: exploiting either the anticoagulant activity of antithrombin (AT), the free radical scavenging activity of alpha-1-microglobulin $(\mathrm{A} 1 \mathrm{M})$, or the regenerative capacity of mesenchymal stem cells (MSCs) [7].

First, a decrease in AT levels has been seen in patients with PE [8]. Since the formation of thrombin is closely linked to inflammation through the thrombin receptors, vasoconstriction can be accompanied by a hypercoagulative state in PE [9]. Canonical correlation analyses have shown that the clinical severity shown in PE is related to hypercoagulativity [9]. Therefore, AT treatment is a possible treatment to improve maternal and fetal condition in PE [9].

Second, higher levels of cell-free fetal hemoglobin $(\mathrm{HbF})$ have been found in placentas of patients diagnosed with PE [10]. HbF has been shown to have properties which promote inflammatory and oxidative tissue damage [11]. A1M has been identified as a reductase and binder of heme- groups and organic radicals [10]. It has properties that can protect cells and tissues in particular against damage from free $\mathrm{Hb}-$, heme-, and oxidative stress [11]. Although increased concentration of $\mathrm{A} 1 \mathrm{M}$ has been found in urine and plasma from women with PE, it is hypothesized that endogenously produced A1M cannot cope with the levels of $\mathrm{HbF}$ and oxidative stress which occur in PE [11]. Further, it has been suggested by Wester-Rosenlöf and colleagues that by intravenous supplementation of recombinant A1M can compensate for increased $\mathrm{HbF}$ and oxidative stress levels may relieve symptomatic clinical expression of PE [11].

Finally, MSCs are adult stem cells with self-renewal and multi lineage differentiation potentials [12]. Human MSCs have shown to exert antinflammatory, immunoregulatory and repair effects in animal models that include models of cardiac disease, lung injury and hypertension [12]. The bone marrow is the major source of MSCs [12]. However, the procedure to obtain MSCs from the bone marrow is invasive, and the number of MSCs reduces with age, limiting the clinical applications of MSCs [12, 13]. It has since been discovered that human umbilical cord blood is rich in MSCs that contain similar features to the MSCs found in bone marrow [12]. Therefore, the regenerative effects of placenta or umbilical cord-derived MSCs could potentially treat the endotoxin-induced hypertension that occurs in preeclamptic patients [12]. The objective of this study was to investigate the use of AT, A1M or MSC's as potential therapies for the treatment of women with HELLP and/ or PE using evidence from non-clinical and clinical studies.

\section{Methods}

We conducted a systematic review of the studies done using AT, A1M or MSCs as potential treatments for severe PE or HELLP. The protocol for this systematic review was registered on PROSPERO International prospective register of systematic reviews (registration number: 42017069324) [14]. This study adheres to PRISMA reporting guidelines and methodology for systematic reviews and meta-analyses [15].

\section{Search strategy}

A search strategy was developed using MESH terms and keywords related to the population and interventions. Ovid MEDLINE and Embase databases were searched 
from inception until May 2017 (see Additional file 1 for full search strategy).

\section{Study selection}

Eligible studies included those with pregnant women who had been diagnosed with PE (high blood pressure and proteinuria), severe PE and/or HELLP syndrome. Studies that included pregnant animals who had been induced to develop preeclamptic or HELLP-like symptoms were also eligible, as well as ex-vivo or in-vitro models. Eligible studies for inclusion used one of the following treatments as the intervention: $\mathrm{AT}, \mathrm{A} 1 \mathrm{M}$ or MSCs (placebo or accepted therapies as comparators). There were no restrictions based on language of the study publication. One or more of the following outcomes were required in the study for it to be included: change in blood pressure, change in proteinuria, gestational week at delivery, or days of prolonged pregnancy. All titles and abstracts were independently screened by two reviewers using Covidence [16], and any inconsistencies were resolved through discussion. A full-text screen of the included studies was then performed. Studies were excluded if both reviewers determined that the articles were irrelevant or adequate translations were not achievable.

\section{Data abstraction and assessment of quality}

Data were abstracted during the second full-text screen from the articles that met all inclusion and exclusion criteria. A data abstraction tool was independently used by both reviewers (SG and KB) to systematically extract information from the included studies. Study design, type of publication, population size, study objective, specific patient population, treatment used and outcomes included for each study and confounding variables adjusted for in the analysis. The Newcastle-Ottawa Scale, the Cochrane risk of bias tool for quality assessment of randomized controlled trials and SYRCLE's risk of bias tool for animal studies were used to investigate potential bias of studies [17-19]. The Newcastle-Ottawa Scale was used to assess cohort and case-control studies, and assessed potential bias in the following categories: selection, comparability and outcome [17]. The Cochrane risk of bias tool was used for randomized control trials (RCTs) and the bias was assessed according to the guidelines as good, fair, or poor quality [18]. The SYRCLE's risk of bias tool was used for animal studies [19]. The inter-observer variability between reviewers for assessing bias was done using Kappa statistics. Six questions were selected from different parts of the data extraction form including; funding source, industry involvement, type of publication, study design, exposure and intervention. The average kappa statistic for these six questions was 0.81 .

\section{Data synthesis and analysis}

A minimum of two RCTs with homogenous outcomes were required to perform a meta-analysis. Where studies included subjects satisfying similar selection criteria, presenting similar outcomes, and defining measurements in a same manner, the effect sizes were synthesized in a fixed effect model. The inverse variance approach was used for continuous data, with standard mean difference as the effect measure. The $I^{\wedge} 2$ statistic along with chi-squared and degrees of freedom were computed to check for heterogeneity among studies included. The test for the overall effect of the model was noted to be statistically significant at $p<0.05$.

Data from RCTs, observational studies, animal studies, and ex vivo studies were also captured in summary Tables.

\section{Results}

Database searches identified 1015 non-duplicate references imported for screening. Their title and abstracts were screened and 962 studies were excluded from the primary screen, which resulted in 53 studies remaining to undergo full-text screening (Fig. 1). After the full-text screen, 17 articles remained in the study. Of these 17 studies, nine investigated the use of AT as the treatment (six RCTs [9, 20-24]), two observational studies [25, 26], and one animal study (reported in two publications [27, 28]). Four investigated the use of A1M as treatment (three animal studies [11, 29, 30] and one ex vivo study [31]), and four investigated the use of MSCs as treatment (three animal studies [12, 32, 33] and one ex vivo study [34]). All human and animal studies looked at the effect of these treatments on PE or induced PE-like symptoms. None of the studies investigated HELLP syndrome.

Of the 17 studies, nine studies were published since 2014, four studies had a publication date between 2000 and 2013, and the remaining four studies had a publication date prior to 2000. Forty-seven percent of the studies were from Asia, $41 \%$ of the studies were from Europe, and $12 \%$ were from North America. Forty-seven percent of the studies were animal studies, $35 \%$ of the studies were RCTs, $12 \%$ were cohort studies, and $12 \%$ were ex-vivo studies.

The most commonly investigated outcome was level of proteinuria, which was an outcome mentioned in six animal studies [12, 27, 29, 30,32, 33] and two human studies [22, 24]. All seven animal studies [11, 12, 27, 29, 30, 32, 33] and one human study reported on blood pressure values [26], six human studies reported gestational age at delivery $[9,20,18,23,24,26]$, and five human studies reported on prolongation of pregnancy from treatment to delivery [20, 22-25].

\section{Assessment of quality}

The Cochrane risk of bias tool was used to assess RCTs [18]. Fifty percent of the studies were rated as having an 


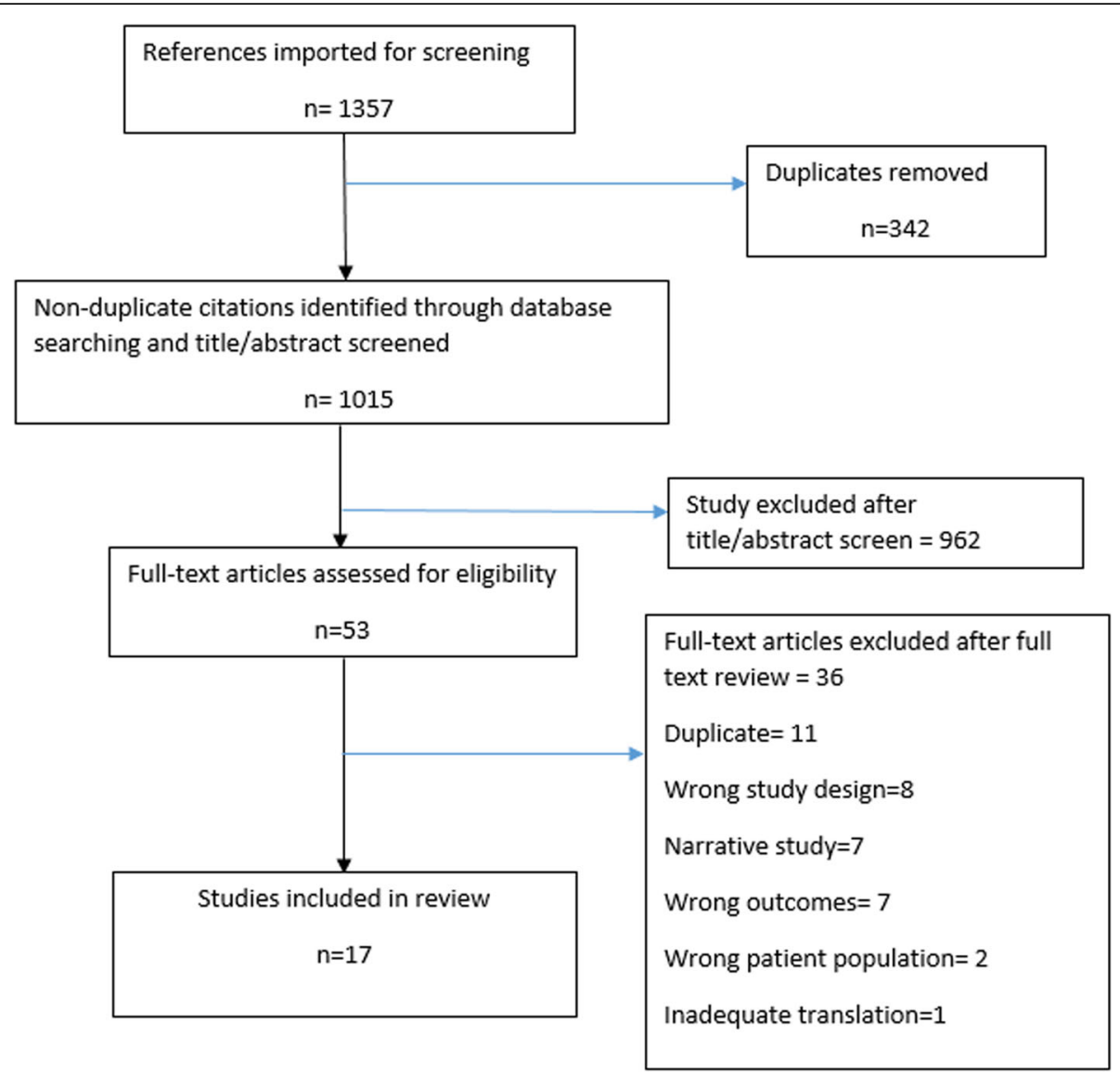

Fig. 1 Preferred Reporting Items for Systematic Reviews and Meta-Analyses (PRISMA) flow diagram showing study selection process

unclear risk of bias for the sequence generation category, with $50 \%$ being rated as having a low risk of bias (Table 1). The same results were obtained for allocation concealment, as well as blinding of participants and personnel. Eighty-three percent of the studies were rated with a low risk of bias for the incomplete outcome data assessed category, with one study (17\%) being rated with an unclear risk of bias. The same results were obtained for the free of selective reporting category. One hundred percent of the studies were rated with a low risk of bias in the free of other bias category.

The Newcastle-Ottawa Scale [17] was used twice for quality assessment on the two cohort studies [25, 26]. These studies received an average of 3 out of 4 stars for

Table 1 Results of assessment of risk of bias for Randomized Control Trials, based on Cochrane risk-of-bias-tool [18]

\begin{tabular}{|c|c|c|c|c|c|c|c|}
\hline Reference & $\begin{array}{l}\text { Sequence } \\
\text { generation }\end{array}$ & $\begin{array}{l}\text { Allocation } \\
\text { concealment }\end{array}$ & $\begin{array}{l}\text { Blinding of participants } \\
\text { and personnel }\end{array}$ & $\begin{array}{l}\text { Blinding of outcome } \\
\text { assessments }\end{array}$ & $\begin{array}{l}\text { Incomplete outcome } \\
\text { data assessed }\end{array}$ & $\begin{array}{l}\text { Free of selective } \\
\text { reporting }\end{array}$ & $\begin{array}{l}\text { Free of } \\
\text { other bias }\end{array}$ \\
\hline $\begin{array}{l}\text { D'Angelo, } \\
2016 \text { [22] }\end{array}$ & Low & Low & Low & Low & Low & Low & Low \\
\hline $\begin{array}{l}\text { Kobayashi, } \\
2003[21]\end{array}$ & Unclear & Unclear & Unclear & Low & Low & Low & Low \\
\hline $\begin{array}{l}\text { Maki, } 2000 \\
{[20]}\end{array}$ & Unclear & Unclear & Low & Low & Low & Low & Low \\
\hline $\begin{array}{l}\text { Sameshima, } \\
2008 \text { [9] }\end{array}$ & Low & Low & Low & Low & Low & Low & Low \\
\hline $\begin{array}{l}\text { Sibai, } 2017 \\
\text { [23] }\end{array}$ & Unclear & Unclear & Unclear & Unclear & Low & Unclear & Low \\
\hline $\begin{array}{l}\text { Paternoster, } \\
2004[24]\end{array}$ & Low & Low & Unclear & Low & Unclear & Low & Low \\
\hline
\end{tabular}


selection, 0 out of 2 stars for comparability, and 1 out of 3 stars for outcome. They both received 5 out of 9 stars total.

The SYRCLE risk of bias tool was used to assess the animal studies [19]. It should be noted that the one animal study which investigation AT was reported in two publications [27, 28]; both are assessed here and the higher quality report [28] was summarized in the results below. Most or all studies were rated as low risk of bias for the group similarities at baseline category, the free of selective reporting category, and the free of other bias category; one was rated as having a high risk of bias (free of selective reporting category), while the rest were rated as unclear (Table 2). Most studies were rated as unclear for the sequence generation category, the allocation concealment category, the random housing of animals' category, and the blinding of caregivers/investigators and outcome assessor category; the rest were rated as low risk of bias (Table 2). Over half the studies were rated as low risk of bias for the random animal selection category, while the rest were rated as unclear (Table 2). Over half the studies were rated as low risk of bias for the outcome assessment category, while the rest were rated as unclear (Table 2).

\section{Antithrombin}

For studies evaluating AT, the population, dose and outcomes reported for the studies are presented in Table 3. Eight of the nine studies studied pregnant women with PE $[9,20-26]$, with the remaining study was conducted in a rat model of PE [28]. The eight human studies varied in their study populations since the inclusion criteria between studies varied with regards to gestational age. The total gestational age range covered in these studies was 23 to 35 weeks. Three human studies used purely
AT as the treatment and placebo as the control $[22,23,25]$. Two human studies used AT alone as the treatment and human albumin as the control $[9,20]$. One human study looked at high dose AT versus a low dose of AT [24]. The remaining two human studies used a combination of AT and heparin as treatment and heparin alone as the control $[21,26]$. The animal study had three study groups, low-dose AT, high-dose AT, and placebo [28].

For the five studies comparing AT versus placebo or human albumin, none of the studies reported values for blood pressure. However, one of the articles [20] includes a gestosis index which combines edema, proteinuria, and blood pressure to make a numerical scale that is used to compare the effectiveness of AT versus placebo on improving these three outcomes. The lower the gestosis index became, the more effective the treatment was. The gestosis index was significantly decreased in the AT treated group. In terms of proteinuria, only one of the studies [22] included numerical values, which did not change significantly with treatment. The other study that investigated proteinuria was Maki, 2000 [20] which incorporated proteinuria into the gestosis index. The gestosis index was significantly decreased in the AT treated group. Of the five studies that reported pregnancy prolongation as an outcome [20, 22-25], one study found that AT prolonged gestation significantly (6.5 days) compared with human albumin $(p<0.01)$ [20]. Another study reported that pregnancy was prolonged in the AT group compared with placebo, although it did not provide data supporting the statement [25]. The remaining three studies did not report any significant differences in pregnancy prolongation between the AT and control groups [22-24].

Table 2 Results of assessment of bias for animal studies, based on SYRCLE risk-of-bias tool [19]

\begin{tabular}{|c|c|c|c|c|c|c|c|c|c|}
\hline Reference & $\begin{array}{l}\text { Sequence } \\
\text { generation }\end{array}$ & $\begin{array}{l}\text { Group } \\
\text { similarities } \\
\text { at baseline }\end{array}$ & $\begin{array}{l}\text { Allocation } \\
\text { concealment }\end{array}$ & $\begin{array}{l}\text { Random } \\
\text { housing of } \\
\text { animals }\end{array}$ & $\begin{array}{l}\text { Blinding of caregivers } \\
\text { and/or investigators and } \\
\text { outcome assessor }\end{array}$ & $\begin{array}{l}\text { Random animal } \\
\text { selection for } \\
\text { outcome } \\
\text { assessment }\end{array}$ & $\begin{array}{l}\text { Incomplete } \\
\text { outcome data } \\
\text { addressed }\end{array}$ & $\begin{array}{l}\text { Free of } \\
\text { selective } \\
\text { reporting }\end{array}$ & $\begin{array}{l}\text { Free } \\
\text { of } \\
\text { other } \\
\text { bias }\end{array}$ \\
\hline $\begin{array}{l}\text { Erlandsson, } \\
2014 \text { [29] }\end{array}$ & Unclear & Low & Unclear & Unclear & Unclear & Low & Unclear & Low & Low \\
\hline $\begin{array}{l}\mathrm{Fu}, 2015 \\
{[12]}\end{array}$ & Low & Low & Unclear & Low & Unclear & Low & Low & Low & Low \\
\hline $\begin{array}{l}\text { Liu, } 2014 \\
\text { [35] }\end{array}$ & Unclear & Low & Unclear & Low & Unclear & Low & Unclear & Low & Low \\
\hline $\begin{array}{l}\text { Naav, } 2015 \\
{[30]}\end{array}$ & Unclear & Unclear & Unclear & Unclear & Unclear & Low & High & Unclear & Low \\
\hline $\begin{array}{l}\text { Shinyama, } \\
1996 \text { [28] }\end{array}$ & Unclear & Low & Unclear & Unclear & Unclear & Unclear & Low & Low & Low \\
\hline $\begin{array}{l}\text { Wang, } 2016 \\
\text { [33] }\end{array}$ & Unclear & Low & Unclear & Unclear & Unclear & Unclear & Low & Unclear & Low \\
\hline $\begin{array}{l}\text { Wester- } \\
\text { Rosenlof, } \\
2014 \text { [11] }\end{array}$ & Low & Low & Low & Unclear & Low & Low & Low & Low & Low \\
\hline
\end{tabular}




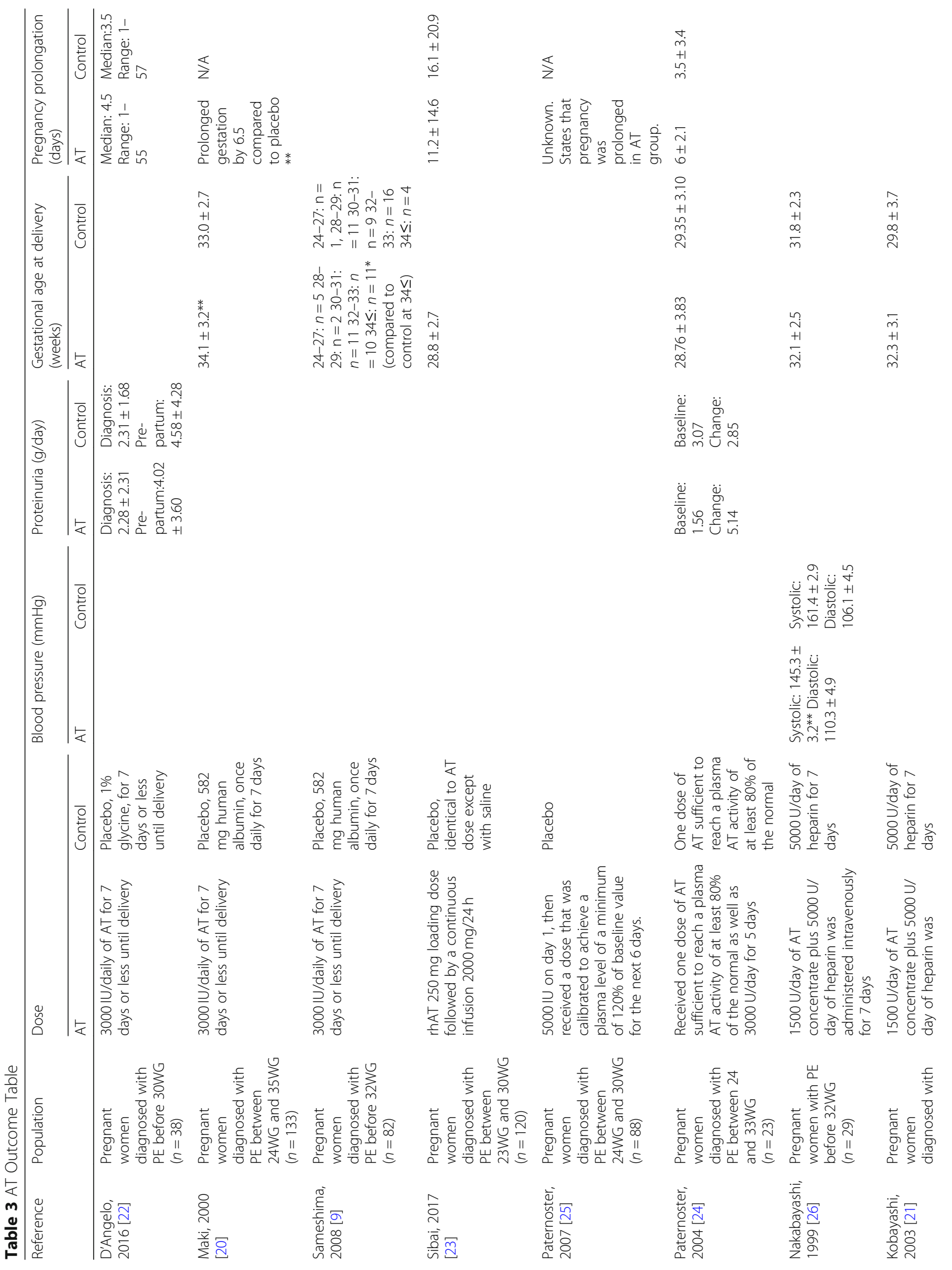




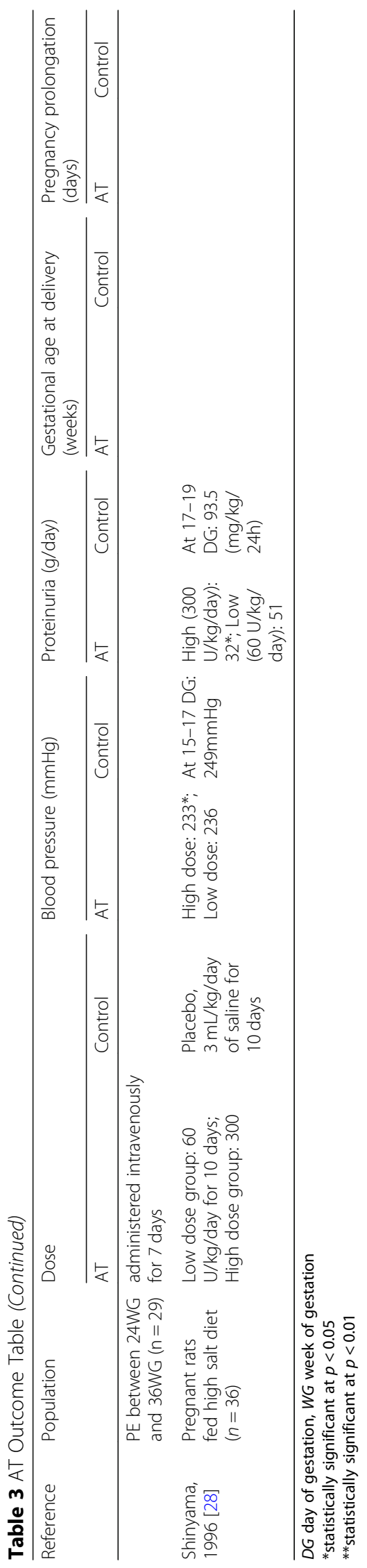


For the two studies comparing AT and heparin versus heparin alone in women with PE $[21,26]$, only one study reported blood pressure as a treatment outcome [26]. This study found that the group treated with AT and heparin had a significantly lower systolic blood pressure compared with the group treated with heparin alone $(p$ $<0.01$ ). Neither studies reported proteinuria values, however, proteinuria was incorporated into the gestosis index of one study [21], which reported that proteinuria was significantly improved in the AT plus heparin treated group. Both studies reported no significant differences in gestational age in the AT and heparin treated group compared with heparin alone.

For the single study that compared high-dose versus low-dose AT in women with PE, no significant differences in proteinuria, gestational age and pregnancy prolongation were observed between study groups [24].

Finally, for the animal study that compared high-dose AT, low-dose AT and placebo in a rat model of PE, a significant improvement in blood pressure and proteinuria was observed in the high-dose AT group (but not the low-dose AT group) compared with placebo [28].

\section{Alpha-1-microglobulin}

For studies evaluating $\mathrm{A} 1 \mathrm{M}$, the population, dose and outcomes reported for the studies are presented in Table 4. The three studies investigating A1M treatment were all animal studies, and used different study animals: mice [29], rabbits [30] and ewes [11]. Various methods were used to achieve preeclamptic-like symptoms seen in pregnant women, such as using transgenetics, administering $\mathrm{HbF}$ infusions, or inducing starvation. However, in the study that used $\mathrm{HbF}$, the blood pressure was not significantly increased to preeclamptic-like levels and therefore the effect of A1M on blood pressure could not be assessed. The treated groups were given different doses of $\mathrm{A} 1 \mathrm{M}$ and all of the control groups used placebo. One study stated that the A1M treatment significantly reduced hypertension and proteinuria throughout pregnancy, though no data was given [29]. Another study showed that the mean arterial blood pressure was significantly lower $(p<0.05)$ than the control group [11]. The level of proteinuria was significantly reduced $(\mathrm{p}<0.05)$ compared to the control in another study [30].

The one ex-vivo study investigating $\mathrm{A} 1 \mathrm{M}$ used $\mathrm{HbF}$ to induce functional and structural damage to human term placentas such as extracellular vesicle release and placental microRNA (miRNA) expression alteration [31]. These changes are seen in PE and are hypothesized to be caused by toxic effects of free $\mathrm{HbF}$ [31]. A1M is thought to be able to counteract the effect that $\mathrm{HbF}$ has on the placentas [31]. Placental tissue was perfused ex-vivo with free $\mathrm{HbF}$ and the miRNA profile in released extracellular vesicles were examined along with the therapeutic effect of A1M. Free $\mathrm{Hb}$ altered the miRNA expression of placental extracellular vesicles. The up-regulated miRNAs; mir-373, mir-372 and mir-527 are all expressed on chromosome 19, close to the placental imprinted gene cluster C19MC [31]. Mir-424 is down-regulated in hypoxic trophoblasts [31]. A1M reduced the $\mathrm{Hb}$ induced changes, suggesting heme scavenging as a potential therapeutic approach in PE [31].

\section{Mesenchymal stem cells}

For studies evaluating MSCs, the population, dose and outcomes reported for the studies are presented in Table 5. The three studies investigating MSC treatment were animal studies, with two studies using rats [12,33] and one study using mice [32]. The treated groups were given different doses of MSCs and all of the control groups were untreated. In the two rat studies, collectively, there were 3 out of 6 days where the blood pressure and the proteinuria was significantly lower $(p<0.05)$ than their control counterparts $[12,33]$. In the one mouse study, there were no significant

Table 4 A1M Outcome Table

\begin{tabular}{|c|c|c|c|c|c|c|c|}
\hline \multirow[t]{2}{*}{ Reference } & \multirow[t]{2}{*}{ Population } & \multicolumn{2}{|l|}{ Dose } & \multicolumn{2}{|l|}{ Blood pressure $(\mathrm{mmHg})$} & \multicolumn{2}{|l|}{ Proteinuria } \\
\hline & & $\mathrm{A} 1 \mathrm{M}$ & Control & $\mathrm{A} 1 \mathrm{M}$ & Control & $\mathrm{A} 1 \mathrm{M}$ & Control \\
\hline $\begin{array}{l}\text { Erlandsson, } \\
2014 \text { [29] }\end{array}$ & $\begin{array}{l}\text { STOX1 } \\
\text { transgene } \\
\text { mouse model } \\
(\mathrm{n}=\mathrm{NR})\end{array}$ & $\begin{array}{l}\text { A1M injections } \\
\text { from DG6 }\end{array}$ & $\begin{array}{l}\text { Placebo, } \\
\text { buffer } \\
\text { solution }\end{array}$ & $\begin{array}{l}\text { Unknown. States that A1M } \\
\text { significantly reduced } \\
\text { hypertension throughout } \\
\text { pregnancy. }\end{array}$ & $\mathrm{N} / \mathrm{A}$ & $\begin{array}{l}\text { Unknown. States that A1M } \\
\text { significantly reduced } \\
\text { proteinuria throughout } \\
\text { pregnancy. }\end{array}$ & $\mathrm{N} / \mathrm{A}$ \\
\hline $\begin{array}{l}\text { Naav, } 2015 \\
{[30]}\end{array}$ & $\begin{array}{l}\text { Rabbits infused } \\
\text { with } 20 \mathrm{mg} / \mathrm{kg} \\
\text { of } \mathrm{HbF}(n=19)\end{array}$ & $6 \mathrm{mg} / \mathrm{kg}$ of $\mathrm{A} 1 \mathrm{M}$ & Nothing & HbF didn't increase BP & & $11 \mu \mathrm{g} / \mathrm{mL}$ of albumin* & $\begin{array}{l}57 \mu \mathrm{g} / \\
\mathrm{mL} \text { of } \\
\text { albumin }\end{array}$ \\
\hline $\begin{array}{l}\text { Wester- } \\
\text { Rosenlof, } \\
2014 \text { [11] }\end{array}$ & $\begin{array}{l}\text { Ewes starved } \\
\text { for } 36 \mathrm{~h}(\mathrm{n}= \\
11)\end{array}$ & $\begin{array}{l}2 \text { bolus doses of } \\
1.8 \mathrm{mg} \mathrm{A} 1 \mathrm{M} / \mathrm{kg} \\
\text { body weight } 2 \mathrm{~h} \\
\text { apart }\end{array}$ & $\begin{array}{l}2 \text { separate } 50 \\
\mathrm{~mL} \text { doses of } \\
\text { buffer } \\
\text { solution }\end{array}$ & $\begin{array}{l}\text { MAP } 36 \text { h post treatment: } \\
58.5^{*}\end{array}$ & $\begin{array}{l}\text { MAP } 36 \mathrm{~h} \\
\text { post } \\
\text { treatment: } \\
73.5\end{array}$ & & \\
\hline
\end{tabular}

RED: Approximate value obtained by graph extrapolation

$M A P$ mean arterial pressure, $D G$ day of gestation, $B P$ blood pressure

*statistically significant at $p<0.05$ 
Table 5 MSCs Outcome Table

\begin{tabular}{|c|c|c|c|c|c|c|c|}
\hline \multirow[t]{2}{*}{ Reference } & \multirow[t]{2}{*}{ Population } & \multicolumn{2}{|l|}{ Dose } & \multicolumn{2}{|c|}{ Blood pressure $(\mathrm{mmHg})$} & \multicolumn{2}{|l|}{ Proteinuria } \\
\hline & & MSC & Control & MSC & Control & $\overline{M S C}$ & Control \\
\hline $\begin{array}{l}\mathrm{Fu}, 2015 \\
{[12]}\end{array}$ & $\begin{array}{l}\text { Rats treated with } 2 \\
\mathrm{~mL} \text { endotoxin }(n= \\
21)\end{array}$ & $\begin{array}{l}\text { MSCs suspended in } \\
100 \mu \mathrm{L} \text { phosphate- } \\
\text { buffered saline }\left(2 \times 10^{6}\right. \\
\text { cells } / 100 \mu \mathrm{L})\end{array}$ & Nothing & $\begin{array}{l}\text { Systolic DG8: } 113 \\
\text { DG15: } 124.5^{*} \\
\text { DG19: } 124.0^{*}\end{array}$ & $\begin{array}{l}\text { Systolic DG8: } 112 \\
\text { DG15: } 131.0 \text { DG19: } \\
\text { 135.5 }\end{array}$ & $\begin{array}{l}\text { DG9: } 3.15 \mathrm{~mol} / \mathrm{L} \\
\text { DG16: } 4.60 \mathrm{~mol} / \mathrm{L}^{*} \\
\text { DG20: } 5.60 \mathrm{~mol} / \mathrm{L}^{*}\end{array}$ & $\begin{array}{l}\text { DG9: } 3.20 \mathrm{~mol} / \mathrm{L} \\
\text { DG16: } 3.65 \mathrm{~mol} / \mathrm{L} \\
\text { DG20: } 3.90 \mathrm{~mol} / \mathrm{L}\end{array}$ \\
\hline $\begin{array}{l}\text { Liu, } 2014 \\
{[32]}\end{array}$ & $\begin{array}{l}\text { Mice injected with } \\
10^{7} \text { activated Th1 } \\
\text { cells at DG10.5 and } \\
\text { DG12.5 }(n=24)\end{array}$ & $\begin{array}{l}\text { MSCs suspended in } \\
100 \mathrm{~mL} \text { of PBS ( } 106 \\
\text { cells/100 mL) injected } \\
\text { on DG } 11.5 \text { and DG } \\
13.5\end{array}$ & Nothing & $\begin{array}{l}\text { Systolic DG14: } \\
135^{* *}\end{array}$ & Systolic DG14: 182 & DG14: $750 \mathrm{mg} / \mathrm{L}$ & DG14: $750 \mathrm{mg} / \mathrm{L}$ \\
\hline $\begin{array}{l}\text { Wang, } \\
2016 \text { [33] }\end{array}$ & $\begin{array}{l}\text { Pregnant rats } \\
\text { treated with } 1 \mu \mathrm{g} / \\
\mathrm{kg} \text { LPS solution }(\mathrm{n} \\
=21)\end{array}$ & $\begin{array}{l}2 \times 10^{6} \mathrm{MSCS} \\
\text { per rat }\end{array}$ & Nothing & $\begin{array}{l}\text { Systolic DG12: } \\
\text { 116.27 } \pm 0.61 \\
\text { DG15: } 125.08+ \\
\text { 3.42 DG18: } 124.29 \\
\pm 3.71^{*}\end{array}$ & $\begin{array}{l}\text { Systolic DG12: } \\
115.65 \pm 1.15 \\
\text { DG15: } 127.41 \pm \\
3.25 \text { DG18: } 139.50 \\
\pm 2.38\end{array}$ & $\begin{array}{l}\text { DG13: } 3.10 \pm 0.71 \\
\mathrm{~mol} / \mathrm{Ln} \mathrm{DG} 16: 3.81 \\
\pm 0.70 \mathrm{~mol} / \mathrm{L} \mathrm{DG} 19: \\
4.54 \pm 0.64 \mathrm{~mol} / \mathrm{L}^{*}\end{array}$ & $\begin{array}{l}\text { DG13: } 3.06 \pm 0.50 \\
\text { mg DG16: } 4.55 \pm \\
0.57 \mathrm{mgn} \text { DG19: } \\
5.56 \pm 1.22 \mathrm{mg}\end{array}$ \\
\hline
\end{tabular}

RED: Approximate value obtained by graph extrapolation

$D G$ day of gestation, LPS Lipopolysaccharide, PBS phosphate buffered saline

*Statistically significant at $p<0.05$

**Statistically significant at $p<0.01$

differences in proteinuria, however, a significant lowering of systolic blood pressure was observed $(p<0.01)$ [35]. The one ex-vivo study investigating MSCs looked at the potential of placenta-derived MSCs to counteract the pro-inflammatory cytokines and anti-angiogenic factors typical of preeclamptic placentae [34]. This study treated PE villous explants with conditioned media collected from cultured placenta-derived MSCs isolated from control placentae. The results showed that normal placenta-derived MSCs conditioned media treatment significantly decreased Macrophage-migration Inhibitory Factor, Tumour Necrosis Factor $\alpha$, Interleukin 6 and anti-angiogenic soluble fms-like tyrosine kinase-1 mRNA levels in PE villous explants relative to untreated controls [34].

\section{Meta-analyses}

A meta-analysis was done amongst the studies that used AT as the treatment. A forest plot with a pooled effect was done to show the results, with the effect size synthesized using a fixed effects model. Meta-analyses for studies using A1M or MSCs were not feasible due to limited number of studies as well as varying patient populations and outcome reporting amongst the studies.

Figure 2 demonstrates the results of pooling RCT data on AT therapy versus placebo in extending gestational age at delivery in women with PE. The pooled effect and 95\% confidence interval can be found at the bottom of Fig. 2, in the same line as "Total". In the right panel of Fig. 2, the cumulative meta-analysis is graphically displayed. The meta-analysis demonstrates that the desired outcome (increased gestational age at delivery) was not favoured in the AT treated group compared with the placebo treated group. However, these results are not significant.

Figure 3 demonstrates the results of pooling RCT data on AT plus heparin therapy versus heparin alone in extending gestational age at delivery in women with PE. The pooled effect and 95\% confidence interval can be found at the bottom of Fig. 3, in the same line as "Total". In the right panel of Fig. 3, the cumulative meta-analysis is graphically displayed. The meta-analysis demonstrates that the desired outcome (increased gestational age at delivery) was not favoured in the AT and heparin treated group compared with the group treated with heparin alone. However, these results are not significant.

\begin{tabular}{|c|c|c|c|c|c|c|c|c|c|c|c|}
\hline \multirow{2}{*}{ Study or Subgroup } & \multicolumn{3}{|c|}{ Antithrombin } & \multicolumn{3}{|c|}{ Placebo } & \multicolumn{2}{|r|}{ Std. Mean Difference } & \multirow{2}{*}{\multicolumn{3}{|c|}{$\begin{array}{l}\text { Std. Mean Difference } \\
\text { IV, Fixed, } 95 \% \mathrm{CI}\end{array}$}} \\
\hline & Mean & SD & Total & Mean & SD & Total & Weight & IV, Fixed, 95\% Cl & & & \\
\hline Kobayashi, 2003 & 34.2 & 2.6 & 14 & 32.4 & 3.7 & 14 & & Not estimable & & & \\
\hline Maki, 2000 & 34.1 & 3.2 & 64 & 33 & 2.7 & 66 & $38.7 \%$ & $0.37[0.02,0.72]$ & & $y=$ & \\
\hline Nakabayashi, 1999 & 32.1 & 2.5 & 14 & 31.8 & 2.3 & 15 & & Not estimable & & & \\
\hline Paternoster, 2004 & 28.76 & 3.83 & 8 & 29.35 & 3.1 & 10 & & Not estimable & & & \\
\hline Sameshima, 2008 & 31.7 & 3.2 & 42 & 31.2 & 2.4 & 42 & $25.3 \%$ & $0.18[-0.25,0.60]$ & & 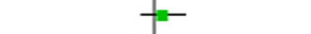 & \\
\hline Sibai, 2017 & 28.8 & 2.7 & 62 & 29.6 & 3.2 & 58 & $36.0 \%$ & $-0.27[-0.63,0.09]$ & & - - -+ & \\
\hline \multirow{2}{*}{\multicolumn{6}{|c|}{$\begin{array}{l}\text { Total }(95 \% \mathrm{Cl}) \\
\text { Heterogeneity: Chi }{ }^{2}=6.48, \mathrm{df}=2(\mathrm{P}=0.04) ; \mathrm{I}^{2}=69 \% \\
\text { Test for overall effect: } \mathrm{Z}=0.82(\mathrm{P}=0.41)\end{array}$}} & 166 & $100.0 \%$ & $0.09[-0.13,0.31]$ & & & \\
\hline & & & & & & & & & -4 & $\begin{array}{ccc}1 & 1 & 1 \\
-2 & 0 & 2 \\
\text { Favours [AT] } & \text { Favours [Plb] }\end{array}$ & 4 \\
\hline
\end{tabular}




\begin{tabular}{|c|c|c|c|c|c|c|c|c|c|}
\hline \multirow[b]{2}{*}{ Study or Subgroup } & \multicolumn{3}{|c|}{ Antithrombin } & \multicolumn{3}{|c|}{ Heparin } & \multicolumn{2}{|r|}{ Std. Mean Difference } & \multirow{2}{*}{$\begin{array}{l}\text { Std. Mean Difference } \\
\text { IV, Fixed, } 95 \% \mathrm{Cl}\end{array}$} \\
\hline & Mean & SD & Total & Mean & SD & Total & Weight & IV, Fixed, $95 \% \mathrm{CI}$ & \\
\hline Kobayashi, 2003 & 34.2 & 2.6 & 14 & 32.4 & 3.7 & 14 & $48.1 \%$ & $0.55[-0.21,1.30]$ & \\
\hline Nakabayashi, 1999 & 32.1 & 2.5 & 14 & 31.8 & 2.3 & 15 & $51.9 \%$ & $0.12[-0.61,0.85]$ & \\
\hline Total $(95 \% \mathrm{Cl})$ & & & 28 & & & 29 & $100.0 \%$ & $0.33[-0.20,0.85]$ & \\
\hline $\begin{array}{l}\text { Heterogeneity: } \mathrm{Ch}^{2}= \\
\text { Test for overall effect }\end{array}$ & $\begin{array}{l}0.63, \mathrm{df} \\
Z=1.2\end{array}$ & $\begin{array}{l}=11 \\
(P=\end{array}$ & $\begin{array}{l}P=0.4 \\
0.22)\end{array}$ & 43 & & & & & $\begin{array}{cccc}1 & 1 & 1 \\
-4 & -2 & 0 & 2 \\
\text { Favours [Antithrombin] } & 4 \text { Favours [Heparin] }\end{array}$ \\
\hline
\end{tabular}

Fig. 3 AT as a potential therapy for PE, Outcome: Gestational age at delivery in patients treated with AT and heparin, versus patients treated with heparin alone

\section{Discussion}

The treatment of PE is more challenging than its prevention. The literature demonstrated that the pathology of PE cannot be completely reversed or terminated. Therefore, current methods of treatment are used to decrease the rate of advancement of the pathological process in order to prolong pregnancy. The current methods used to treat PE include treating hypertension, aspirin and control of blood sugar and renal function [36].

From a review by El Sayed published in 2017 [36], the following medications have proven safe and effective in prolonging pregnancy in women with PE: esomeprazole, which potently decreases soluble fms-like tyrosine kinase 1 and soluble endoglin secretion from placenta and endothelial cells, and has biological actions to mitigate endothelial dysfunction and oxidative stress [37]; metformin, an inhibitor of hypoxic inducible factor-1a [38]; sildenafil, a vasodilator [39]; curcumin, an anti-Toll-like receptor-4 [40]; and, hydroxyl-chloroquine, an antagonist of tumour necrosis factor-a [41]. However, these drugs used individually in PE have only been able to prolong pregnancy for 2-4days, albeit a sufficient time frame to allow for a single course of steroid therapy which has been shown to improve fetal outcomes [42]. Although, the efficacy of using multiple medications is unknown, and could prove to prolong pregnancy even further in these women, there still remains an unmet need for a successful treatment option.

The current study evaluated the literature for evidence relating to three potential new treatment options for PE: AT, A1M, and MSCs. A systematic review of the literature provided limited data for these treatment options, with clinical data only being available for AT. Unfortunately, a meta-analysis that included six clinical studies comparing AT and placebo in women with PE demonstrated no difference between the two study groups for gestational age at delivery. Furthermore, when data from two studies comparing AT with heparin versus heparin alone were combined, no difference in gestational age at delivery was observed between the two study groups. Regarding $\mathrm{A} 1 \mathrm{M}$, data from the animal studies were variable with benefits observed for some but not all outcomes. For MSCs, benefits were observed in a majority of outcomes with a significant decrease in blood pressure shown in all three animal studies, and a significant decrease in proteinuria demonstrated in two out of three of the animal studies.

At the time of finalizing this manuscript (August 2018) a search of the literature was performed using relevant key words to see if any new publications existed in the topic area. Two studies were identified [43, 44]. The first study evaluated the biological function of MSCs for the treatment of angiotensin receptor agonistic autoantibody-induced hypertension during pregnancy in a rat model [43]. The study found that MSCs ameliorated induced hypertension, intrauterine growth retardation, kidney damage, and spiral artery remodeling impairment [43]. The second study demonstrated that A1M had a protective effect on kidneys in a mouse model of acute kidney injury [44]. The same study also constructed a novel recombinant A1M with superior solubility and stability, and suggested it was a better drug candidate for treating acute kidney injury and preeclampsia [44]. Both these studies, although not retrieved during the systematic review process, support the benefits of A1M and MSCs that we observed in our findings.

This study was strengthened by a rigorous search strategy. However, our results and the strength of our conclusions are limited by the number of relevant studies [16], and the number of relevant human studies [7]. In addition, evaluations were inconsistent and/or lacking across studies. For example, no human studies reported on normal-term delivery but instead reported on gestational age at delivery or pregnancy prolongation. Furthermore, no human studies reported on all four outcomes of interest in the same study (blood pressure, proteinuria, pregnancy stage, and biomarkers), with most human studies reporting on just a few outcomes. In fact, biomarkers were only evaluated in the ex vivo studies and only one of the human studies reported on blood pressure. Lastly, numerical values for the outcomes of interest were not always available which resulted in values being extrapolated from graphs which introduced a percent of error to these data.

\section{Conclusions}

In conclusion, the results of this review are limited by the quantity and quality of evidence available but are 
supported by a thorough systematic search and review of the literature. According to the current systematic review, at this time, it appears that clinical data do not support using AT as a treatment option for PE. Regarding A1M and MSCs, animal and ex vivo studies identified in this review provide data to support pilot clinical studies of both of these agents in women with PE. However, our review suggests that the current experimental data favors MSCs over A1M.

\section{Additional file}

Additional file 1: Search Strategy. Additional details of the primary search strategy developed using Ovid MEDLINE and EMBASE (DOCX 72 kb)

\begin{abstract}
Abbreviations
A1M: alpha-1-microglobulin; AT: antithrombin; BP: blood pressure; HbF: fetal hemoglobin; HELLP: Hemolysis, Elevated Liver enzymes, Low Platelet count: miRNA: microRNA; MSC: mesenchymal stem cell.; PE: preeclampsia; $\mathrm{RCT}$ : randomized controlled trial
\end{abstract}

\section{Acknowledgments}

Not applicable.

\section{Funding}

This study was supported by Canadian Institutes of Health Research (CIHR) (Grant Number FDN-148438). The funding body had no role in the design of the study, collection, analysis, interpretation of data, writing the manuscript, or decision to publish.

Design of the study, collection, analysis, interpretation of data, and in writing the manuscript.

\section{Availability of data and materials}

The datasets used and/or analysed during the current study are available from the corresponding author on reasonable request.

\section{Authors' contributions}

SG: made substantial contributions to conception and design, or acquisition of data, or analysis and interpretation of data; been involved in drafting the manuscript or revising it critically. KB: made substantial contributions to conception and design, or acquisition of data, or analysis and interpretation of data; been involved in drafting the manuscript. MW, AL, DC: made substantial contributions to conception and design, or analysis and interpretation of data; been involved in revising the manuscript critically; and, given final approval of the version to be published. All authors read and approved the final manuscript.

\section{Ethics approval and consent to participate}

Not applicable.

\section{Consent for publication}

All authors have consented to the publication of this systematic review.

\section{Competing interests}

The authors declare that they have no competing interests.

\section{Publisher's Note}

Springer Nature remains neutral with regard to jurisdictional claims in published maps and institutional affiliations.

\section{Author details}

'OMNI Research Group, Clinical Epidemiology Program, Ottawa Hospital Research Institute, Ottawa, Ontario, Canada. ${ }^{2}$ School of Epidemiology, Public Health and Preventive Medicine, University of Ottawa, Ottawa, Ontario, Canada. ${ }^{3}$ Department of Obstetrics, Gynecology \& Newborn Care, University of Ottawa, Ottawa, Ontario, Canada. ${ }^{4}$ Children's Hospital of Eastern Ontario
Research Institute, Ottawa, Ontario, Canada. ${ }^{5} \mathrm{OMNI}$ Research Group, Centre for Practice Changing Research, Ottawa Hospital Research Institute, L1242, Box 241, 501 Smyth Road, Ottawa, ON K1H 8L6, Canada.

Received: 12 November 2018 Accepted: 27 March 2019

Published online: 09 May 2019

\section{References}

1. Ngwenya S. Severe preeclampsia and eclampsia: incidence, complications, and perinatal outcomes at a low-resource setting, Mpilo central hospital, Bulawayo, Zimbabwe. Int J Womens Health. 2017;9:353-7. https://doi.org/10. 2147/IJWH.S131934.

2. Duley L. The global impact of pre-eclampsia and eclampsia. Semin Perinatol. 2009;33(3):130-7. https://doi.org/10.1053/j.semperi.2009.02.010.

3. Hansson SR, Nääv $\AA$, Erlandsson L. Oxidative stress in preeclampsia and the role of free fetal hemoglobin. Front Physiol. 2014;5:516. https://doi.org/10. 3389/fphys.2014.00516.

4. Abildgaard U, Heimdal K. Pathogenesis of the syndrome of hemolysis, elevated liver enzymes, and low platelet count (HELLP): a review. Eur J Obstet Gynecol Reprod Biol. 2013;166(2):117-23. https://doi.org/10.1016/j. ejogrb.2012.09.026.

5. Benedetto C, Marozio L, Tancredi A, et al. Biochemistry of HELLP syndrome. Adv Clin Chem. 2011;53:85-104 http://www.ncbi.nlm.nih.gov/pubmed/21404915.

6. Godfrey KM, Barker DJ. Fetal nutrition and adult disease. Am J Clin Nutr. 2000;71(5 Suppl):1344S-52S http://www.ncbi.nlm.nih.gov/pubmed/ 10799412.

7. Hahn S. Preeclampsia - will orphan drug status facilitate innovative biological therapies? Front Surg. 2015;2:7 http://ovidsp.ovid.com/ovidweb. cgi?T=JS\&PAGE=reference\&D=prem\&NEWS=N\&AN=25767802.

8. Terao T, Maki M, Ikenoue $\mathrm{T}$, et al. The relationship between clinical signs and hypercoagulable state in toxemia of pregnancy. Gynecol Obs Invest. 1991;31(2):74-85.

9. Sameshima $H$, Kodama $Y$, Ikenoue $T$, Kajiwara $Y$. Antithrombin improves fetal condition in women with severe pre-eclampsia before 32 weeks of gestation; a randomized, double-blind, placebo-controlled trial. J Obstet Gynaecol Res. 2008;34(1):34-9. https://doi.org/10.1111/j.1447-0756.2007.00677.x.

10. Gunnarsson R, Åkerström B, Hansson SR, Gram M. Recombinant alpha-1microglobulin: a potential treatment for preeclampsia. Drug Discov Today. 2017:22(4):736-43. https://doi.org/10.1016/j.drudis.2016.12.005.

11. Wester-Rosenlöf $L$, Casslén $V$, Axelsson J, et al. A1M/\$a\$1-microglobulin protects from Heme-induced placental and renal damage in a pregnant sheep model of preeclampsia. Long D, ed. PLoS One. 2014;9(1):e86353. https://doi.org/10.1371/journal.pone.0086353.

12. Fu L, Liu Y, Zhang D, Xie J, Guan H, Shang T. Beneficial effect of human umbilical cord-derived mesenchymal stem cells on an endotoxin-induced rat model of preeclampsia. Exp Ther Med. 2015;10(5):1851-6. https://doi.org/ 10.3892/etm.2015.2742.

13. Charif N, Li YY, Targa L, et al. Aging of bone marrow mesenchymal stromal/ stem cells: implications on autologous regenerative medicine. Stoltz J-F, Magdalou J, Bensoussan D, eds. Biomed Mater Eng. 2017;28(s1):S57-63. https://doi.org/10.3233/BME-171624.

14. Stewart L, Moher D, Shekelle P. Why prospective registration of systematic reviews makes sense. Syst Rev. 2012;1 (1):7. https://doi.org/10.1186/2046-4053-1-7.

15. Shamseer $L$, Moher $D$, Clarke $M$, et al. Preferred reporting items for systematic review and meta-analysis protocols (PRISMA-P) 2015: elaboration and explanation. BMJ. 2015;349(3):g7647. https://doi.org/10.1136/bmj.g7647.

16. Covidence - better systematic review management. https://www.covidence. org/home. Accessed 8 Aug 2018.

17. Wells GA, Shea B, O'Connell D, et al. The Newcastle-Ottawa scale (NOS) for assessing the quality of nonrandomized studies in meta-analyses. Ottawa Hosp Res Inst. 2013;(3):1-4. https://doi.org/10.2307/632432.

18. Higgins JPT, Altman DG, Gøtzsche PC, et al. The Cochrane Collaboration's tool for assessing risk of bias in randomised trials. BMJ. 2011;343:d5928. https://doi.org/10.1136/bmj.d5928.

19. Hooijmans CR, Rovers MM, De VRBM, Leenaars M, Ritskes-hoitinga M, Langendam MW. SYRCLE'M s risk of bias tool for animal studies. BMC Med Res Methodol. 2014;14(1):1-9. https://doi.org/10.1186/1471-2288-14-43.

20. Maki M, Kobayashi T, Terao T, et al. Antithrombin therapy for severe preeclampsia: results of a double-blind, randomized, placebo-controlled trial. B151.017 study group. Thromb Haemost. 2000;84(4):583-90 http://www.ncbi. nlm.nih.gov/pubmed/11057854. Accessed 2 Apr 2018. 
21. Kobayashi T, Terao T, Ikenoue T, et al. Treatment of severe preeclampsia with antithrombin concentrate: results of a prospective feasibility study. Semin Thromb Hemost. 2003;29(6):645-52.

22. D'Angelo A, Valsecchi L, Group A-EPS. High dose antithrombin supplementation in early preeclampsia: a randomized, double blind, placebo-controlled study. Sampietro F Marchesoni D, Lovotti M, Frusca T, Telloli P, Marozio L, Anna S, Raffaelli R, Bacci M FF, ed. Thromb Res. 2016;140:7-13.

23. Sibai B, Paidas MJ. LB02: randomized double-blind placebo controlled evaluation of the safety and efficacy of recombinant Antithrombin versus placebo in preterm preeclampsia. Am J Obstet Gynecol. 2017;216(1):S559-60. https://doi.org/10.1016/j.ajog.2016.11.1048.

24. Paternoster DM, Fantinato S, Manganelli F, Milani M, Nicolini U, Girolami A Efficacy of AT in pre-eclampsia: a case-control prospective trial. Thromb Haemost. 2004;91(2):283-9.

25. Paternoster DM, Fantinato S, Visentin S, Celleno D, Mangione S, Fasolino A, Branconi F, Nicolini U. Trattamento della preelampsia precoce con concentrato di antitrombina. Studio multicentrico in aperto. Ital J Gynecol Obstet. 2007;19(1):45-9.

26. Nakabayashi M, Asami M, Nakatani A. Efficacy of antithrombin replacement therapy in severe early-onset preeclampsia. Semin Thromb Hemost. 1999; 25(5):463-6. https://doi.org/10.1055/s-2007-994951.

27. Shinyama H, Akira T, Uchida T, Hirahara K, Watanabe M, Kagitani Y. Antithrombin III prevents renal dysfunction and hypertension induced by enhanced intravascular coagulation in pregnant rats: pharmacological confirmation of the benefits of treatment with antithrombin III in preeclampsia. J Cardiovasc Pharmacol. 1996;27(5):702-11 http://www.ncbi. nlm.nih.gov/pubmed/8859941. Accessed 2 Apr 2018.

28. Shinyama H, Yamanaga K, Akira T, et al. Antithrombin III prevents blood pressure elevation and proteinuria induced by high salt intake in pregnant stroke-prone spontaneously hypertensive rats. Biol Pharm Bull. 1996;19(6):819-23.

29. Erlandsson L, Doridot L, Ducat A, et al. Alpha-1 microglobulin as a potential therapeutic candidate for the treatment of preeclampsia. Placenta. 2014; 35(9):A78. https://doi.org/10.1016/j.placenta.2014.06.253.

30. Nääv $\AA$, Erlandsson L, Axelsson J, et al. A1M ameliorates preeclampsia-like symptoms in placenta and kidney induced by cell-free fetal hemoglobin in rabbit. Simeoni U, ed. PLoS One. 2015;10(5):e0125499. https://doi.org/10. 1371/journal.pone.0125499.

31. Cronqvist $T$, Salje $K$, Veerla $S$, et al. Placental extracellular vesicles' micro-RNA profile, is altered by free hemoglobin and restored by alpha-1microglobulin. Placenta. 2012;33(9):A73.

32. Liu L, Zhao G, Fan H, et al. Mesenchymal stem cells ameliorate Th1-induced pre-eclampsia-like symptoms in mice via the suppression of TNF-\$a\$ expression. Jeong J, ed. PLoS One. 2014;9(2):e88036. https://doi.org/10.1371/ journal.pone.0088036.

33. Wang L-L, Yu Y, Guan H-B, Qiao C. Effect of human umbilical cord mesenchymal stem cell transplantation in a rat model of preeclampsia. Reprod Sci. 2016;23(8):1058-70.

34. Nuzzo AM, Giuffrida D, Piccoli E, et al. Anti-inflammatory and proangiogenic effects of placental mesenchymal stromal cells conditioned media on preeclamptic placental tissue. Placenta. 2014;35(9):A87. https://doi. org/10.1016/j.placenta.2014.06.280.

35. Liu L, Zhao G, Fan H, et al. Mesenchymal stem cells ameliorate Th1-induced pre-eclampsia-like symptoms in mice via the suppression of TNF-alpha expression. PLoS One. 2014;9(2):e88036.

36. El-Sayed AAF. Preeclampsia: a review of the pathogenesis and possible management strategies based on its pathophysiological derangements. Taiwan J Obstet Gynecol. 2017;56(5):593-8. https://doi.org/10.1016/j.tjog. 2017.08.004

37. Cluver CA, Walker SP, Mol BW, et al. Double blind, randomised, placebocontrolled trial to evaluate the efficacy of esomeprazole to treat early onset pre-eclampsia (PIE trial): a study protocol. BMJ Open. 2015;5(10):e008211. https://doi.org/10.1136/bmjopen-2015-008211.

38. Brownfoot FC, Hastie R, Hannan NJ, et al. Metformin as a prevention and treatment for preeclampsia: effects on soluble fms-like tyrosine kinase 1 and soluble endoglin secretion and endothelial dysfunction. Am J Obstet Gynecol. 2016;214(3):356.e1-356.e15. https://doi.org/10.1016/j.ajog.2015.12.019.

39. Bujold E, Leblanc V, Lavoie-Lebel É, et al. High-flavanol and hightheobromine versus low-flavanol and low-theobromine chocolate to improve uterine artery pulsatility index: a double blind randomized clinical trial. J Matern Fetal Neonatal Med. 2017;30(17):2062-7. https://doi.org/10. 1080/14767058.2016.1236250.
40. Gong P, Liu M, Hong G, et al. Curcumin improves LPS-induced preeclampsialike phenotype in rat by inhibiting the TLR4 signaling pathway. Placenta. 2016 41:45-52. https://doi.org/10.1016/j.placenta.2016.03.002.

41. Rahman $R$, Murthi $P$, Singh $H$, et al. The effects of hydroxychloroquine on endothelial dysfunction. Pregnancy Hypertens An Int J Women's CardiovasC Heal. 2016;6(4):259-62. https://doi.org/10.1016/j.preghy.2016.09.001.

42. Roberts D, Brown J, Medley N, Dalziel SR. Antenatal corticosteroids for accelerating fetal lung maturation for women at risk of preterm birth. Cochrane Database Syst Rev. 2017;3:CD004454. https://doi.org/10.1002/ 14651858.CD004454.pub3.

43. Zhang D, Fu L, Wang $L$, et al. Therapeutic benefit of mesenchymal stem cells in pregnant rats with angiotensin receptor agonistic autoantibodyinduced hypertension: implications for immunomodulation and cytoprotection. Hypertens pregnancy. 2017;36(3):247-58. https://doi.org/10. 1080/10641955.2017.1329429

44. Åkerström B, Rosenlöf L, Hägerwall A, et al. rA1M-035, a Physicochemically improved human recombinant a1-microglobulin, has therapeutic effects in rhabdomyolysis-induced acute kidney injury. Antioxid Redox Signal 2018:ars. 2017.7181. doi:https://doi.org/10.1089/ars.2017.7181.

\section{Ready to submit your research? Choose BMC and benefit from:}

- fast, convenient online submission

- thorough peer review by experienced researchers in your field

- rapid publication on acceptance

- support for research data, including large and complex data types

- gold Open Access which fosters wider collaboration and increased citations

- maximum visibility for your research: over $100 \mathrm{M}$ website views per year

At BMC, research is always in progress.

Learn more biomedcentral.com/submissions 